\title{
Crisis Costs \& Debtor Discipline: the efficacy of public policy in sovereign debt crises
}

\author{
Prasanna Gai, Simon Hayes ${ }^{\dagger} \&$ Hyun Song Shin ${ }^{\ddagger}$ \\ February 7, 2002
}

\begin{abstract}
Recent debate on the reform of the international financial architecture has highlighted the potentially important role of the official sector in crisis management. We examine how such public intervention in sovereign debt crises affects efficiency, ex ante and ex post. Our results shed light on the scale of capital inflows in such a regime, and we establish conditions under which this leads to an improvement in debtor country welfare. The efficacy of measures such as officially sanctioned stays on creditor litigation depend critically on the quality of public sector surveillance and the size of the costs of sovereign debt crises.
\end{abstract}

\section{Introduction}

There has been considerable debate on the reform of the international financial architecture in the aftermath of recent crises. Academics and policy-makers alike have advocated a number of measures to prevent crises, or at least limit their frequency and severity. They include improvements in national balance sheet management to avoid severe currency and maturity mismatches, the provision of contingent credit lines for emergency official finance, and the development of codes and standards to allow better-informed decisions by debtors and creditors. ${ }^{1}$

*Research School of Pacific \& Asian Studies, Australian National University, ACT 0200, Australia. Email: prasanna.gai@anu.edu.au

$\dagger$ International Finance Division, Bank of England, London EC2R 8AH, UK.

$¥$ Department of Accounting \& Finance, London School of Economics, Houghton St, London WC2A 2AE, UK.

${ }^{1}$ An overview of the policy debate is offered in Drage and Mann (1999). 
By contrast, progress on public policies aimed at improving the process of crisis resolution has been slower, reflecting the difficulties inherent in promoting cooperative solutions between a sovereign debtor and its international creditors. Nevertheless, a broad consensus may be developing around the central objective of international crisis management, namely the restoration of confidence and the normal flow of private capital to the debtor.

There has also been a measure of agreement on the circumstances under which crises arise. The academic literature on financial crises has typically identified two main (and separate) causes. ${ }^{2}$ First, inconsistent government policies and/or external shocks can bring about a secular deterioration in a country's fundamentals leading, for example, to an unsustainable build-up of debt or the exhaustion of foreign exchange reserves, thereby triggering a crisis. Second, crises may reflect a coordination problem among creditors - the actions of creditors can be mutually reinforcing as they 'race for the exits'. The important role of creditor beliefs is therefore highlighted. Pessimistic expectations can become both self-generating and self-fulfilling. ${ }^{3}$ Reflecting these two lines of thinking, public policy approaches to crisis management have recognised the possible need for debt restructuring in cases where crises arise from poor performance and policy, laying stress on the important role of official finance in support of credible policy adjustment. And they have sought to limit investor panics by seeking to coordinate private creditors, for example by agreeing to roll over obligations coming due.

In practice, crisis management is likely to require a judicious mix of private sector involvement and official finance. ${ }^{4}$ But the method of achieving this mix is far from clear-cut. On one view, there is a danger that too rigid a set of rules would act as an unhelpful constraint. Crises arise for different reasons and differ in form, so should be approached on a case-by-case basis. An alternative viewpoint is that too much discretion increases uncertainty about possible outcomes in the event of a crisis. For example, lack of clarity regarding the amount, timing and conditionality of official sector lending may compound the disorder in the workout process. If guidelines create an expectation of orderly crisis management, this may reduce the likelihood of sharp reversals in capital flows in circumstances where

\footnotetext{
${ }^{2}$ See Krugman (1979), Diamond and Dybvig (1983), and Obstfeld (1996). Flood and Marion (1998) offer a comprehensive survey.

${ }^{3}$ Recent work by Morris and Shin $(1998,2000)$ on the co-ordination problem underlying financial crises shows how fundamentals and beliefs intertwine. The policy implications, for sovereign liquidity crises, of this approach are examined in Chui, Gai and Haldane (2002).

${ }^{4}$ See, for example, Summers (2000).
} 
debtor fundamentals are perceived to be poor.

Some policy-makers have increasingly begun to advocate more active officialsector involvement in international financial crisis resolution. ${ }^{5}$ For example, King (1999) stresses the need to avoid the costs of disorderly liquidation by creditors following a sovereign default and suggests that, in the absence of formal mechanisms, bodies such as the IMF could provide support to a country that has temporarily suspended payments to its creditors. Such support might take the form of lending into arrears and/or assisting in the workout process to ameliorate problems of creditor coordination. Critics, however, argue that if such policies were to become part of the international financial architecture, creditors may reduce investment in emerging markets.

In a recent paper, Dooley (2000) argues that the recent policy debate has focused too much on the amelioration of ex post inefficiencies, and has paid insufficient attention to the moral hazard problems of enforcing sovereign debt. Unlike corporate debt, the lack of collateral (or the means to seize it) means that a threat is necessary to provide the incentive for repayment of sovereign debt. ${ }^{6}$ Drawing on Bolton and Scharfstein (1996), Dooley notes that an optimal structure for international debt needs to balance two concerns: on the one hand, it should deter strategic default; and on the other, it should not make unavoidable ('bad luck') defaults too costly. In Dooley's model, the incentive to repay debt is provided by the protracted loss in output caused by a creditor run. Thus the coordination problem among private creditors, and the associated economic cost for the debtor, is the feature of the international financial system that makes international lending possible. ${ }^{7}$ The implication of Dooley's analysis is that policies designed to eliminate the welfare costs that follow from debt crises could reduce, or even do away with, international debt flows. Optimal public policy intervention therefore needs to balance issues of ex ante and ex post efficiency: it should encourage adherence to the ex ante provisions of contracts while seeking to maximise the ex post value of the debtor.

The analytical foundations of official sector intervention in crisis management

\footnotetext{
${ }^{5}$ An overview of the policy debate on standstills and stays is provided in IMF (2000).

${ }^{6}$ See Eaton and Gersovitz (1981) for the seminal analysis of a sovereign debtor's incentives to repay.

${ }^{7}$ The incentive effects of a threat to terminate lending is discussed in Stiglitz and Weiss (1983). In a related argument in the literature on banking, Calomiris and Kahn (1991) argue that the threat of withdrawal of demand deposits provides an instrument for disciplining bank managers. Diamond and Rajan (2000) use similar intuition in their analysis of the role of short-term debt in recent financial crises.
} 
have yet to be explored exhaustively. In what follows, we develop a theoretical model to analyse some of the incentive effects and trade-offs surrounding policy intervention. ${ }^{8}$ It attempts to assess how public intervention in sovereign debt crises could affect the scale of capital flows and, importantly, the expected output of the debtor country. More specifically, we describe a regime in which, following a sovereign default, the official sector may choose to implement policies to mitigate the ensuing costs to the debtor country. Our model clarifies the conditions under which such a regime leads to an improvement in expected output for the debtor, relative to a regime without such measures. It is cast in the general guise of the trade-off between ex ante and ex post efficiency in the design of the debt contract between the debtor and its creditors, in which a shortfall in debt repayments leads to creditors forcing costly liquidation of investment projects, with negative consequences for the debtor country's output. Two important additional elements in a regime with policy intervention, however, are the official sector's ability to judge the predominant cause of crisis, and the effectiveness with which it can limit costly liquidation. The official sector thus plays the twin roles of whistle-blower and fire fighter. ${ }^{9}$ The first role helps enforce discipline on the debtor ex ante by curtailing "strategic" default, while the second mitigates the ex post costs of a crisis in the event of a "bad luck" default.

Whereas collective action clauses and workout guidelines naturally come into play once a debtor has defaulted, the official sector is likely to intervene only when the debtor country's finances are judged to be genuinely inadequate to honour its debt obligations. So the efficacy of a crisis management framework is likely to depend critically on the quality of this judgment. The policy is ineffectual, and indeed counter-productive, if the quality of official sector assessments of a debtor country's circumstances is poor. The effectiveness of intervention also depends importantly on the ability of the official sector to limit the costs of liquidation. The absence of a coherent framework with which to mitigate the costs of crisis may mean that official sector intervention could be unsuccessful in influencing the basic trade-off between ex ante and ex post efficiency, even if its judgment is sound.

The paper proceeds as follows. Section 2 describes the basic framework of

\footnotetext{
${ }^{8}$ Dooley and Verma (2001), Miller and Zhang (1999), and Kumar, Masson and Miller (2000) have recently analysed the role of the official sector in crisis management. In a complementary analysis, Bolton and Rosenthal (1999) also emphasise the trade-off between ex ante and ex post efficiency in a model of debt moratoria.

${ }^{9}$ Clementi (2000) describes the fire-fighting analogy in greater detail.
} 
the model and establishes the incentive-compatible level of lending in a regime without official intervention. We illustrate the main arguments made by critics of such measures, and show how lending varies with the output costs of a crisis. In Section 3, we introduce the official sector into the model and compare incentivecompatible lending under the two regimes. We show how imperfect monitoring by the official sector can lead to a lower level of lending ex ante. The marketbased level of lending is shown to be replicable only if the official sector is able to gauge perfectly the state of nature in the debtor country. Although ex ante lending is likely to be lower in a world with official involvement, an exclusive focus on capital inflows is inappropriate. Section 3 also establishes conditions under which expected output is higher under a regime with crisis-management policies. Expected output can be higher because the benefits of intervention are felt most in adverse circumstances, i.e bad states of nature. The greater the ex post inefficiency from debt crises, the more beneficial such a regime is likely to be. A final section discusses the policy implications of our findings, and concludes with suggestions for future work.

\section{Basic model}

Our model is an account of the interaction between a single debtor country and a continuum of small creditors. The debtor has no resources of its own and can produce only if it is able to obtain loans. It has access to a production technology that transforms loans into output. There are three dates, initial, interim and final (dates 0,1 and 2 respectively). At the initial date (date 0 ), the debtor is granted a loan of size $L$, and promises to repay interest and principal, $r L$ at the interim date (date 1). For now, we treat the repayment rate $r$ as being exogenous, returning later to endogenise it. When amount $L$ is invested at date 0 , the project generates an interim output at date 1 , which is used to repay the creditors. The final output depends on the amount repaid by the debtor at the interim date. If the debtor

pays the full promised amount $r L$, then the project is allowed to mature without intervention from the creditors. However, if there is a shortfall in the amount repaid, creditors can force costly liquidation commensurate with the amount of the shortfall. The damage caused by the forced liquidation will depend on factors such as the extent of collateralisation of the debt or the amount of debtor assets that can be seized in the creditor country. If we denote by $x$ the amount repaid by the debtor at the interim date, the proportional discretionary shortfall $s$ is the 
amount repudiated as a proportion of the amount owed, ie

$$
s=\frac{r L-x}{r L} .
$$

Output in the final period (date 2) is assumed to be a function of the scale of the initial investment $L$, and the extent of the costly liquidation arising from $s$ at date 1 . We denote the output in the final period by

$$
y(L, s)
$$

which we assume to be strictly decreasing in $s$. Our formulation captures, in a reduced-form fashion, the costs associated with disorderly liquidation. As stressed by Stiglitz and Weiss (1983), Bolton and Scharfstein (1990, 1996), and Allen and Gale (1998), liquidation or the termination of lending can be costly, and acts as a way of inducing the debtor country to repay creditors instead of diverting resources to itself.

The debtor may choose to repay the full amount if the interim output is sufficient, but we leave open the possibility that the debtor will choose not to honour its promise, and to repudiate some or all of its debt obligations even though it can afford to repay in full. But if the interim output falls short of the repayment amount $r L$, then the debtor is forced into defaulting on some of its debt. Thus there is the possibility that a payment shortfall is due to bad luck. Whether the non-payment is intentional or the result of bad luck is not verifiable for the purpose of the loan contract between the debtor and the borrowers.

The interim output $\tilde{x}$ of the debtor is a random variable, the distribution of which is common knowledge and the realisation of which is the private information of the borrower. It takes the value $r L$ with probability $\theta$, but is uniformly distributed on the interval $[0, r L]$ with probability $1-\theta$. In other words, there is a probability $\theta$ that the debtor has sufficient resources to pay back the loan in full. However, with probability $1-\theta$, there are insufficient resources to repay. In this event, the amount of the shortage in resources is uniformly distributed over the possible range. We let

$$
z=\frac{r L-\tilde{x}}{r L}
$$

denote the size of the proportional natural shortfall in resources at the interim date. Then $z$ is a random variable that takes the value of 0 with probability $\theta$ and is uniformly distributed on the unit interval with probability $1-\theta$. The shortfall in the amount actually repaid may be larger than $z$ (since the debtor may choose 
not to repay all of this output), but the shortfall in the actual repayment cannot be smaller than $z$, since the debtor cannot repay more than can be afforded.

\subsection{Optimal contract}

The optimal size of loan, $L$, for the debtor maximises the expected output net of the repayment costs, taking into account the possible disruptions caused by premature liquidation. Denoting by $\mathrm{E}(\cdot)$ the expectations operator associated with the random variable $z$, the optimal contract selects the loan size $L$ to maximise:

$$
\mathrm{E}[y(L, z)-(1-z) r L]
$$

subject to two sets of constraints. The first is the participation constraint

$$
\mathrm{E}[y(L, z)-(1-z) r L] \geq 0
$$

which requires that the debtor be better off with the debt contract than without. The second set of constraints are the incentive-compatibility constraints which require that

$$
y(L, z)-(1-z) r L \geq y(L, s)-(1-s) r L
$$

for all $z$ and all $s \geq z$. If there is no resource shortage (ie $z=0$ ), the debtor has an incentive to pay back the full amount to the lender. Equation (6) also ensures that if Nature has dealt a resource shortage of $z$, the debtor has no incentive to keep back any of the realised output from the creditors.

The incentive-compatibility constraints specified above are particularly strong and ensure that the optimal contract is such that it is never optimal for the debtor to default strategically in any state. This generates a level of lending that cannot be surpassed. The expected output of the debtor that is associated with this amount of lending provides a useful, although extreme, benchmark with which to compare the effects of crisis management policies. ${ }^{10}$

\subsection{Parametric example}

In what follows, we solve the optimal contracting problem for a parametric example. Specifically, we examine the case where $y(L, s)$ takes the form:

$$
y(L, s) \equiv(1-\alpha s) L^{\lambda}
$$

\footnotetext{
${ }^{10}$ This contrasts with other models of sovereign debt, eg Eaton \& Gersovitz (1981) and Grossman \& van Huyck (1988), which show that strategic default may be optimal in some states of nature.
} 
where $\alpha$ and $\lambda$ are parameters satisfying $0<\alpha<1$ and $0<\lambda<1$. The parameter $\alpha$ captures the extent of the damage done by the premature liquidation by the creditors at the interim date. If there is repudiation of $s$, the output at the final period is reduced by a factor of $\alpha s .{ }^{11}$ The parameter $\lambda$ determines the elasticity of final output with respect to the size of initial investment $L$.

The incentive-compatibility constraints (6) can be given a simple characterisation in this context. Given the realisation of $z$ (the realised shortage in resources), the debtor decides on the amount of the actual shortfall $s$ in the repayment to the creditors, subject to $s$ being no smaller than $z$. The debtor's problem is therefore to maximise

$$
(1-\alpha s) L^{\lambda}-(1-s) r L
$$

subject to $s \geq z$. Since equation (8) is linear in $s$, the debtor would choose to repay all of the available resources at the interim date if $\alpha L^{\lambda}>r L$, but would choose to repudiate all of its debt if $\alpha L^{\lambda}<r L$. So the set of incentive-compatibility constraints (6) can be reduced to a single condition on the size of the loan $L$. The initial loan must be small enough so that $\alpha L^{\lambda} \geq r L$. Rearranging, gives

$$
L \leq\left(\frac{\alpha}{r}\right)^{\frac{1}{1-\lambda}}
$$

It remains to determine when the constraint (9) will be binding in the optimal contract. The unconstrained maximisation of the objective function (4) entails solving for $L$ that maximises:

$$
\theta\left[L^{\lambda}-r L\right]+(1-\theta)\left\{[1-\alpha \mathrm{E}(z \mid z>0)] L^{\lambda}-[1-\mathrm{E}(z \mid z>0)] r L\right\}
$$

where $\mathrm{E}(z \mid z>0)$ is the expectation of $z$ conditional on its being strictly positive. Since $z$ is uniformly distributed on the unit interval in this case, $\mathrm{E}(z \mid z>0)=1 / 2$. The solution to the unconstrained maximisation can then be obtained from the first-order condition:

$$
\lambda L^{\lambda-1}\left[\theta+(1-\theta)\left(1-\frac{\alpha}{2}\right)\right]-r\left[\theta+\frac{1-\theta}{2}\right]=0
$$

which yields

$$
L=\left\{\frac{\lambda}{r} \cdot \frac{[2-\alpha(1-\theta)]}{1+\theta}\right\}^{\frac{1}{1-\lambda}} .
$$

\footnotetext{
${ }^{11}$ The output loss in the final period can, of course, also be regarded as a metaphor for the reduction in the future output stream resulting from a loss of market access and reputation.
} 
The incentive-compatibility constraint (9) fails to bind if and only if $\alpha \geq \lambda[2-$ $\alpha(1-\theta)] /(1+\theta)$, or

$$
\alpha \geq \frac{2 \lambda}{1+\theta+\lambda(1-\theta)}
$$

Thus, if $\alpha$ is large enough, there are no impediments to borrowing the ex ante optimal amount. The threat that arises from the effects of premature liquidation by the lenders is enough to discipline the borrower to repay as much as possible. Knowing this, the creditors are prepared to lend the full amount. Conversely, if $\alpha$ is too small, incentive problems limit the amount of borrowing. This feature of our model suggests that in a world of standstills, or similar policies that seek to promote orderly ex post renegotiations, the aggregate flow of lending could well be lower owing to incentive problems. ${ }^{12}$

To complete the solution of the optimal contract, we need to check that the participation constraint (5) is satisfied for positive levels of the loan $L$. This is straightforward in our context, since the production function satisfies $\lim _{L \rightarrow 0} \partial y / \partial L=$ $\infty$, so that the optimal loan $L$ is given by an interior solution. Thus, to summarise, the solution to the optimal contract in our model is given by

$$
L_{*}=\min \left\{\left(\frac{\alpha}{r}\right)^{\frac{1}{1-\lambda}},\left(\frac{\lambda}{r} \frac{[2-\alpha(1-\theta)]}{1+\theta}\right)^{\frac{1}{1-\lambda}}\right\} .
$$

\subsection{Endogenising the repayment rate}

So far, we have treated the repayment rate $r$ as being an exogenous parameter. In a world with default on the part of the debtors, it would not be appropriate to view $r$ as a 'world interest rate'. Instead, it should reflect the credit risk inherent in lending in our model. When the initial loan of $L$ is the solution to the optimal contracting problem, the incentive-compatibility constraints are satisfied so that the amount repaid is equal to the amount of resources available at the interim date. The expected repayment by the borrower under the optimal contract is therefore given by

$$
\theta r L+(1-\theta) r L \cdot \mathrm{E}(1-z \mid z>0)=r L\left(\frac{1+\theta}{2}\right) .
$$

\footnotetext{
${ }^{12}$ The idea that incentive problems have an adverse effect on lending is not new. See, for example, Allen (1983), Kletzer (1984), and Dooley (2000).
} 
For competitive risk-neutral lenders, their expected profit is driven down to zero. In this case, the actuarially fair repayment rate $r$ is given by

$$
r=\left(\frac{2}{1+\theta}\right) .
$$

Substituting this expression into (13) allows us to solve for the optimal contract in terms of the fundamentals of the model.

\section{The role of the public sector in crisis management}

Although the disciplining role of the threat of a disorderly creditor run allows the borrower greater access to credit, it comes at a substantial cost. If the borrower is genuinely unlucky and is forced into default by adverse conditions, and if the potential damage that the coordination problem inflicts on the economy, $\alpha$, is large, the implications for the real and financial sectors of the economy may be severe. Merely to focus on the incentive mechanism determining the access to credit markets understates the potential role that public policy can play in crisis management. Public policy can potentially have a two-fold effect. First, it is possible that increased scrutiny from the official sector may substitute for private sector discipline, by distinguishing publicly between 'bad luck' and 'strategic' defaults. Such 'whistle-blowing' can help to ensure ex ante good behaviour by the debtor. Second, if the framework for public intervention is effective, policy-makers can mitigate ex post coordination costs, ie act as 'firefighters'. Such an effect might be achieved, for example, by providing limited official finance, mediating in workouts, or endorsing temporary controls on capital outflows. In fact, as we now demonstrate, public sector actions that mitigate the costs of disorderly liquidation may well be capable of generating similar levels of lending as the regime in which the threat of termination by private creditors is the sole source of discipline on the debtor's willingness to repay. Taken together, these two effects can generate an improvement in expected output for the debtor.

To illustrate this, we introduce a third party, assumed to be a representative of the international financial community, which we refer to as the 'IMF'. The IMF has no role in the initial period when the loan $L$ is granted to the borrower, but has a role at the interim date. It has access to an imperfect signal concerning the state of the borrower's finances at the interim date. Specifically, it has a signal as to whether the borrower has sufficient resources to pay the loan in full - that is, whether $z$ is zero or positive. Based on this information, the IMF gives a 
pronouncement of its view of the current state of fundamentals and reaches a judgment about the need for official intervention. We assume that the IMF's message space is coarse, consisting of only two messages $\{\mathrm{Good}, \mathrm{Bad}$. The joint distribution over the messages and the underlying state of fundamentals $z$ is given by the following matrix.

\begin{tabular}{|l|l|c|c|}
\hline \multicolumn{2}{|c|}{} & \multicolumn{2}{|c|}{ Message that fundamentals are } \\
\cline { 3 - 4 } \multicolumn{2}{|c|}{ Fundamentals } & Good & Bad \\
\cline { 2 - 4 } & Good $(z=0)$ & $\theta(1-\varepsilon)$ & $\theta \varepsilon$ \\
\cline { 2 - 4 } & Bad $(z>0)$ & $(1-\theta) \varepsilon$ & $(1-\theta)(1-\varepsilon)$ \\
\hline
\end{tabular}

The IMF's signal is imperfect in two senses. First, the message space is binary, merely indicating whether the fundamentals are good or bad. Second, even this binary signal suffers from noise. Conditional on $z=0$, the IMF gets the incorrect message that the fundamentals are 'bad' with probability $\varepsilon$. We assume that $\varepsilon<$ 0.5 , implying that the signal has some information value. There is an analogous probability of mistaking $z>0$ (ie bad fundamentals) for good fundamentals. The parameter $\varepsilon$ indicates the degree of noise in the IMF's signal.

Crucially, if there is a shortfall in the repayment to the creditors, the announcement by the IMF that the fundamentals are bad prompts the implementation of policies to limit or offset the destructive effect of creditor liquidation. The effects of these actions are captured in our model in reduced-form fashion by the parameter $\sigma$ (see below), which reflects the extent to which the public sector is able to reduce the output losses generated by forced liquidation. In essence, $\sigma$ can be interpreted as measuring the efficacy of the official community's framework for crisis management.

In terms of our model, IMF intervention has several effects. We list them below.

- One consequence of policy intervention is to attenuate the effect of the parameter $\alpha$, thereby mitigating the costs of disorderly liquidation by the creditors. In particular, we assume that the IMF action reduces this parameter by a factor $\sigma$, where $0 \leq \sigma \leq 1$. Thus output in the final period given shortfall $s$ when the IMF has intervened is given by

$$
(1-\sigma \alpha s) L^{\lambda}
$$

- When the IMF's decision to intervene is correct (the event represented by the bottom right-hand cell of the matrix), the debtor's true resources $\tilde{x}$ 
become verifiable to the IMF, so that the creditors receive the true realisation of $\tilde{x}$. This means that the realised payment shortfall $s$ is equal to the true shortage of resources given by realisation of the random variable $z$. In other words, the IMF provides discipline consistent with the incentivecompatibility constraint.

- But it is also possible that the IMF intervenes because it mistakenly attributes any deliberate default as having arisen from bad luck (the event given by the top right-hand cell of the matrix). In other words, the IMF mistakenly believes that any shortfall in payment $s$ is due to a lack of resources, and does not recognise that the shortfall has arisen from diversion of funds. Creditors are inappropriately locked in to the workout process, the IMF acts to ameliorate the impact of liquidation, and the debtor cheats successfully.

- Finally, when the IMF mistakenly fails to intervene (the event represented by the bottom left-hand cell of the matrix), it makes the opposite error. Even though the shortfall in payment is due to bad luck, it mistakenly believes that the shortfall is due to diversion of funds and its failure to intervene exposes the country to the full impact of a creditor grab-race.

The consequences of introducing the IMF into our model are twofold. On the one hand, by reducing the costs of disorderly liquidation in the event of default, the IMF can mitigate output costs when $z$ is positive. However, there is a cost arising from the reduced disciplining effect of default, leading to a sub-optimal level of initial credit. The net benefit of the IMF arises only if the first effect outweighs the second.

\subsection{Optimal contract in the presence of the IMF}

The possibility that the IMF will intervene, and thereby mitigate the costs of disorderly liquidation, entails a more stringent set of incentive-compatibility conditions in the choice of loan size $L$. Let us first consider the incentives facing the borrower with $z=0$ - that is, the borrower who has sufficient resources to repay in full. Conditional on $z=0$, the IMF will mistakenly intervene with probability $\varepsilon$, while with probability $1-\varepsilon$, there is no intervention. Thus, the debtor's maximisation problem is to choose $s \geq 0$ so as to maximise:

$$
(1-\varepsilon)\left[(1-\alpha s) L^{\lambda}-(1-s) r L\right]+\varepsilon\left[(1-\sigma \alpha s) L^{\lambda}-(1-s) r L\right]
$$


which can be written as

$$
L^{\lambda}\{1-s \underbrace{\alpha[(1-\varepsilon)+\sigma \varepsilon]}_{\hat{\alpha}}\}-(1-s) r L .
$$

Comparing with (8), the effect of the IMF's presence in the optimisation problem for the debtor is to multiply the factor $\alpha$ by $(1-\varepsilon)+\sigma \varepsilon$, which is strictly less than 1 . Thus we have the following incentive-compatibility condition for the debtor with $z=0$ analogous with (9), where $\hat{\alpha}$ is the shorthand for $\alpha[(1-\varepsilon)+\sigma \varepsilon]$.

$$
L \leq\left(\frac{\hat{\alpha}}{r}\right)^{\frac{1}{1-\lambda}}
$$

Let us now consider a debtor with $z>0$. The debtor knows that the IMF will (correctly) intervene with probability $1-\varepsilon$, but will fail to intervene with probability $\varepsilon$. If intervention is called correctly, the IMF can verify the true realisation of $z$, and enforce payment of the true available resources. Thus the only event in which the debtor's choice of $s$ matters is when the IMF fails to intervene. The debtor's net expected output is given by

$$
\varepsilon\left[(1-\alpha s) L^{\lambda}-(1-s) r L\right]+(1-\varepsilon)\left[(1-\sigma \alpha z) L^{\lambda}-(1-z) r L\right]
$$

and the objective is to choose $s \geq z$ to maximise this expression. Following the same argument as before leads to the incentive-compatibility constraint

$$
L \leq\left(\frac{\alpha}{r}\right)^{\frac{1}{1-\lambda}}
$$

which is identical to the incentive constraint (9) facing the borrower in the regime without the IMF. In particular, since $\hat{\alpha}<\alpha$ the constraint (20) never binds in the optimal contract that satisfies (18), and we may safely neglect it.

The intuition for why the second incentive constraint does not bind is easily conveyed. When $z=0$, the debtor knows that the IMF may intervene incorrectly, in which case there is a positive gain from cheating. As long as this possibility exists, the temptation to cheat weakens the disciplining effect of disorderly liquidation, so that the debtor's access to the credit market is curtailed. In contrast, when $z>0$, the debtor realises that the IMF will (correctly) intervene with high probability, in which case the true resources are revealed and disorderly liquidation is averted. The only event in which cheating may have an effect is when the 
IMF mistakenly fails to intervene, since there is then no relief from the damaging effect of disorderly liquidation and the incentive not to cheat is as high as in the regime without the IMF. The incentive constraint is consequently relaxed, explaining why (20) does not bind.

It remains for us to determine when the incentive-compatibility constraint (18) binds. Note that the solution to the unconstrained problem is identical to the unconstrained problem without the IMF, given by (13), since the IMF does not affect the underlying fundamental features of the economy. Also, as before, the participation constraint does not bind in our model. So the solution to the optimal contracting problem is the level of the loan given by

$$
\hat{L}_{*}=\min \left\{\left(\frac{\hat{\alpha}}{r}\right)^{\frac{1}{1-\lambda}},\left(\frac{\lambda}{r} \frac{[2-\alpha(1-\theta)]}{1+\theta}\right)^{\frac{1}{1-\lambda}}\right\}
$$

where we have used the notation $\hat{L}_{*}$ to indicate the solution to the optimal contracting problem in the presence of the IMF. Comparing this expression with (13), we see that the presence of the IMF reduces the amount of credit available to the borrower. The difference between $\hat{L}_{*}$ and $L_{*}$ depends on two factors: the quality of the IMF's judgment regarding the debtor's fundamentals, represented by $\varepsilon$; and the efficacy of the IMF's actions to limit the effects of liquidation, represented by $\sigma$. These two factors work in different ways. On the one hand, as the IMF's judgment tends to perfection $(\varepsilon \rightarrow 0)$, the discipline of IMF surveillance increasingly substitutes for market discipline in the no-IMF case, and lending in the regime with policy intervention approaches the market solution $(\hat{\alpha} \rightarrow \alpha$ so that $\hat{L}_{*} \rightarrow L_{*}$ ). On the other hand, the lower the effectiveness of official sector involvement in limiting the costliness of liquidation $(\sigma \rightarrow 1)$, the more irrelevant the IMF's involvement becomes in determining creditor and debtor payoffs - if there is little or no reduction in ex post inefficiency, the degree of debtor moral hazard becomes negligible, and once again we see that $\hat{L}_{*} \rightarrow L_{*}$. But apart from these extremes, the borrower cannot get full access to credit and so is worse off, representing an inefficient outcome relative to the market-based solution.

\subsection{Expected output}

Having examined the detrimental effect of the IMF's presence, we now examine the main beneficial effect of the IMF's presence - namely its ability to mitigate the ex post inefficiencies that result from a 'bad luck' default. In particular, we examine the total expected output with and without the IMF. 
Denote by $W$ the (ex ante) total expected output in the regime without the IMF, and by $\hat{W}$ the (ex ante) total expected output in the presence of the IMF. Then, from (13) and (21), and the fact that $\mathrm{E}(z \mid z>0)=1 / 2$ :

$$
\begin{aligned}
W & =L_{*}^{\lambda}\left\{\theta+(1-\theta)\left(1-\frac{\alpha}{2}\right)\right\} \\
\hat{W} & =\hat{L}_{*}^{\lambda}\left\{\theta+(1-\theta)\left[\varepsilon\left(1-\frac{\alpha}{2}\right)+(1-\varepsilon)\left(1-\frac{\sigma \alpha}{2}\right)\right]\right\} \\
& =\hat{L}_{*}^{\lambda}\left\{\theta+(1-\theta)\left(1-\frac{\alpha}{2}[\varepsilon+\sigma(1-\varepsilon)]\right)\right\} .
\end{aligned}
$$

Although $\hat{L}_{*} \leq L_{*}$ (the level of the loan is lower with the IMF), we also have $\alpha[\varepsilon+\sigma(1-\varepsilon)]<\alpha$ (the effect of default is mitigated with IMF), so that there is no general ranking of expected output in the two cases. Whether the IMF has a net beneficial effect depends on the parameters of the model. We will focus, in particular, on the relative rankings of the two regimes as a function of the noise parameter $\varepsilon$. We ask how sound the judgment of the IMF has to be (as captured by the noise parameter $\varepsilon$ ) in order for it to have a net beneficial effect.

The expected output in the absence of the IMF does not depend on $\varepsilon$. However, $\hat{W}$ depends on $\varepsilon$, both because the level of the loan is affected by it, but also because $\varepsilon$ affects the degree of mitigation of the harmful effects of bad luck default. From (21), we see that $\hat{L}_{*}$ is decreasing in $\varepsilon$, while $\varepsilon+\sigma(1-\varepsilon)$ is increasing in $\varepsilon$. Thus, for both reasons, the expected output in the presence of the IMF is a strictly decreasing function of $\varepsilon$. Intuitively, when $\varepsilon$ is large, the scope for errors of judgment by the IMF is significant. Access to the credit market for the borrower is reduced, and the ex post intervention is less effective after default. In the extreme case where $\varepsilon=0$ (when the IMF never gets it wrong), we know that

$$
\hat{L}_{*}=L_{*} \quad \text { but } \quad \sigma \alpha<\alpha
$$

implying that

$$
\hat{W}>W
$$

Since $\hat{W}$ is a continuous function of $\varepsilon$, this implies that for sufficiently small $\varepsilon$, the IMF has a net beneficial effect on expected output. The question is how small $\varepsilon$ must be for this to hold. Denoting by $\hat{W}(\varepsilon)$ the expected output in the IMF regime expressed as a function of $\varepsilon$, we can answer this question by solving for $\varepsilon$ from the equation

$$
\hat{W}(\varepsilon)=W
$$




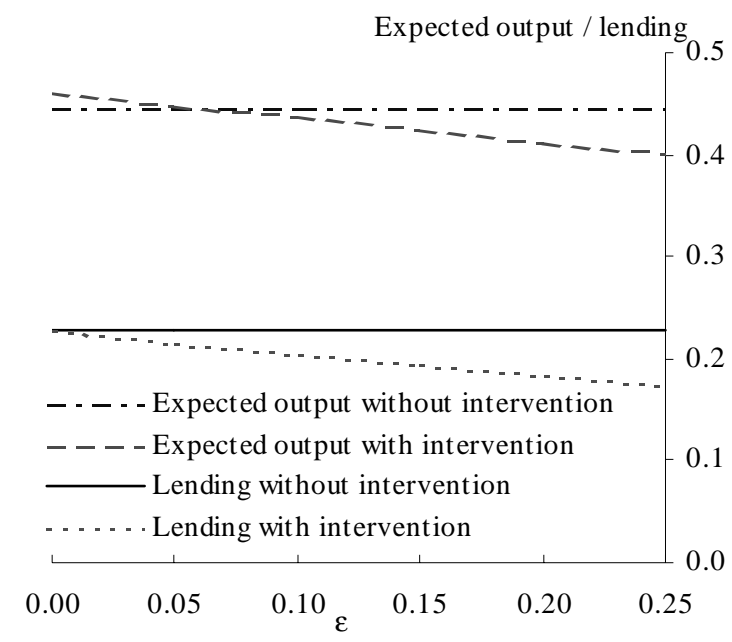

(a) Other parameter values are as follows: $\alpha=0.5, \lambda=0.5$, $\rho=0.05, \theta=0.75, \sigma=0.5$.

Figure 1: The impact of policy intervention on lending and expected output ${ }^{(a)}$

Given the highly non-linear nature of this equation, simple closed-form solutions are not available. Nevertheless, we can gain intuition from some numerical examples. Figure 1 shows how, for chosen benchmark levels, lending and expected output differ in a regime with and without IMF intervention. If the ability of the official sector to judge the state of the debtor country's finances is perfect $(\varepsilon=0)$, the level of lending in the two regimes is the same. But expected output under the regime with IMF intervention is higher because the official sector is correctly able to stem a country run in the case of 'bad luck' default. However, as the quality of judgment declines, both lending and expected output fall and, for sufficiently high values of $\varepsilon$, a regime with intervention may actually reduce expected output. Nevertheless, if judgment error is sufficiently small, intervention can raise expected output. Moreover, as Figure 2 shows, the benefits of intervention are higher when the real cost of the creditor coordination problem $(\alpha)$ is higher.

Figure 3 illustrates the importance of the official community's dual role as 'whistleblower' and 'firefighter'. It again compares expected output in a regime with IMF intervention to expected output in a regime without. This time, however, we examine the effects of varying the efficacy of crisis management policies 


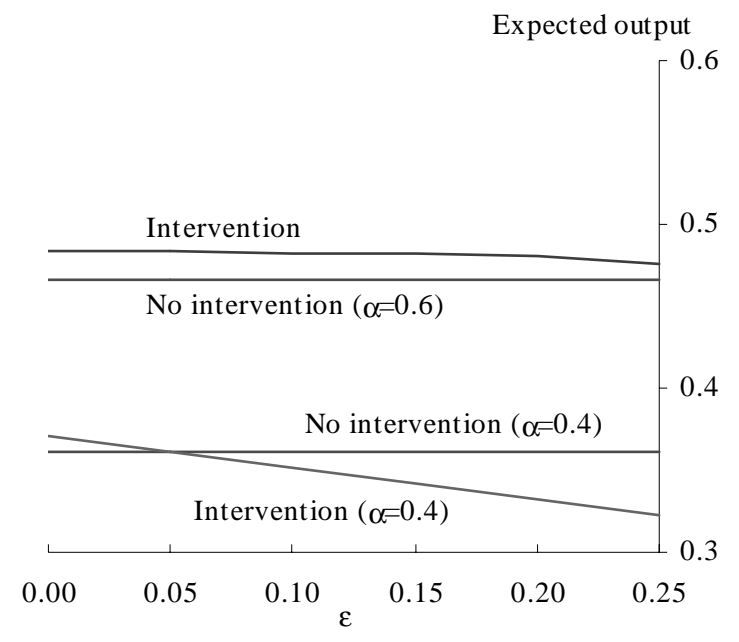

(a) Other parameter values are as follows: $\lambda=0.5, \rho=0.05$, $\theta=0.75, \sigma=0.5$.

Figure 2: Expected output and the costs of disruption ${ }^{(a)}$

$(\sigma)$, for given levels of judgment error $(\varepsilon)$ and output cost $(\alpha)$. It is assumed that the costs of the creditor coordination problem are high, $\alpha=0.6$. As can be seen, in the case where the IMF's judgment is perfect $(\varepsilon=0)$ but its ability to mitigate the coordination costs of crisis is poor $(\sigma \rightarrow 1)$, expected output in the two regimes is the same. But as the ability of the official community to contain the costs of crisis improves $(\sigma \rightarrow 0)$, expected output in a regime with intervention rises above that in a regime without. If the IMF is less than perfect in exercising judgment $(\varepsilon=0.2, \varepsilon=0.3$ in Figure 3$)$, expected output in a regime with intervention can still be higher than with no intervention, as the value of a reduced cost of crisis outweighs the effect of lower lending. But if $\sigma \rightarrow 0$, expected output in the IMF regime falls below that in a no-IMF world. This is because the moral hazard effects created by the combination of weak public monitoring and extremely effective crisis management overwhelm the gains from the elimination of the creditor coordination problem. Although the sensitivity of expected output to the choice of parameters is a reminder of the trap of taking estimates from a simple model too seriously, the qualitative features of our model serve as a useful starting-point for future research. 


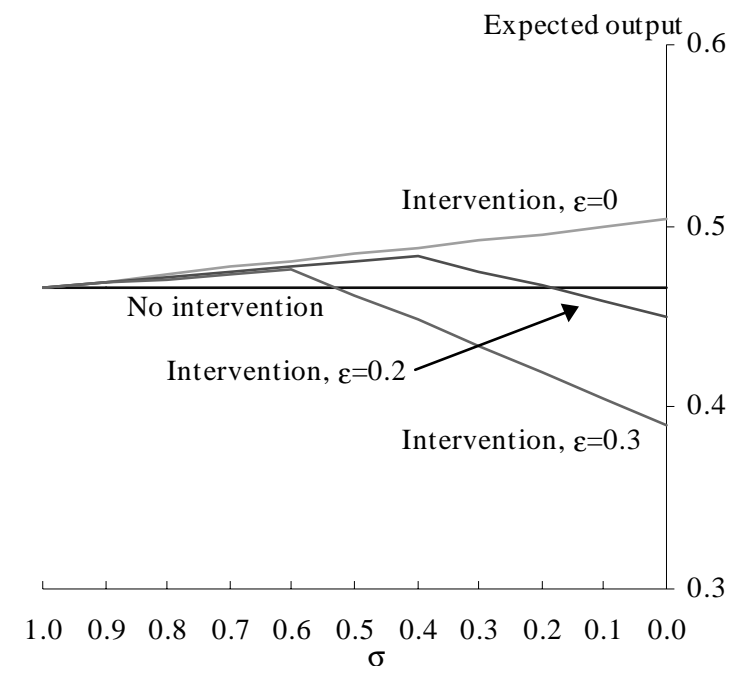

(a) Other parameter values are as follows: $\lambda=0.5, \rho=0.05$, $\theta=0.75, \alpha=0.6$.

Figure 3: Expected output and the efficacy of measures to mitigate disruption $\operatorname{costs}^{(a)}$

\subsection{Case-by-case intervention}

One of the drawbacks of our binary signal framework is that a full analysis of the debate on 'case-by-case' intervention becomes rather difficult. In our binary signal framework, such a policy amounts to intervening in only a subset of those cases for which the policy-maker has received a 'bad' signal. The only way that we could do this is in terms of a a mixed strategy in which the policy-maker only intervenes with some probability $p$ upon receiving a bad signal. This would yield the result that case-by-case intervention is an intermediate policy stance, both in terms of the amount of loans advanced in equilibrium, and also in the expected output.

A more satisfactory framework to examine this issue would be one in which the signal received by the IMF has many values, so that it makes sense to talk about varying degrees of certainty that the fundamentals of the debtor country is good or bad. Case-by-case intervention would amount to a policy in which intervention takes place only when the signal is sufficiently strong that the underlying fundamentals is one of bad luck default. In such a framework, the decision 
of the IMF is to choose the optimal cut-off point for the value of the signal at which intervention takes place. If a policy of case-by-case intervention allows the IMF to choose this cut-off optimally given the joint distribution over signals and outcomes, this would bring benefits over a regime in which the cut-off is set at an artificially low level.

Alternatively, another way to frame the debate on the case-by-case approach is to suppose that there are cross-sectional differences in the noise parameter $\varepsilon$ across debtor countries. Some countries may have high $\varepsilon$ due to the opaqueness of their disclosure policies, for instance. Then, a case-by-case approach would imply a partitioning of debtor countries in terms of the size of their $\varepsilon$. Then only countries that satisfy certain pre-conditions (for example, of providing sound information about fundamentals) are eligible for IMF support in a crisis. In terms of our model, the implication is that intervention should take place only when $\varepsilon$ is less than some (low) critical threshold value. Again, our findings point in favour of a competent and coherent crisis management framework.

Whether we pursue the "strength of signals" interpretation, or the interpretation in terms of the cross sectional differences in $\varepsilon$, a richer modelling strategy would be called for. We believe that extensions along these directions would yield interesting insights.

\section{Policy implications and conclusions}

The model outlined above, although simple, sheds some light on the recent policy debate on crisis resolution measures. Some policy makers emphasise the benefits of policy measures such as temporary standstills and stays on creditor litigation, arguing that they can provide a breathing space that curbs disorderly and costly debt workouts. By contrast, private creditors frequently oppose such proposals, arguing that regimes that include such measures discourage much-needed adjustment effort by debtor countries, and reduce capital flows to emerging economies.

We argue, however, that official-sector intervention based on systematic guidelines could bring welfare benefits to individual debtor economies. Although the introduction of such measures may reduce the level of capital inflows ex ante, it could compensate for this by ameliorating the disruptive effects of crises ex post. The benefits of regimes with policy intervention are most likely to accrue if the official sector is capable of identifying the source of financial problems and utilising emergency finance effectively.

The model is useful for exploring how public sector actions can affect the 
trade-offs inherent in sovereign debt contracts. The sensitivity of the results to parameter values means that unambiguous welfare conclusions about different regimes cannot be reached. But the analysis raises some important general issues about the nature of official involvement in sovereign debt crises. It shows, for example, how the efficacy of proposals on crisis management depend critically on the quality of public sector monitoring of debtor country conditions. The disciplining effect plays an important part in determining the ex ante terms of the debt contract, ie the level of lending and the conditions of the loan. The greater the transparency and accountability of debtor governments, the more effective public monitoring is likely to be. So our results underline the critical role played by IMF surveillance and data disclosure by debtor countries.

Although our model shows that there may be clear gains under a regime with crisis management measures, these gains accrue solely to the debtor country. In our set-up, creditors are indifferent between outcomes. But as Scharfstein and Stein (1990) note, a banker's ability to place loans is fundamental to his/her standing in the labour market. A regime that lowers capital inflows to emerging markets may, in fact, be welfare reducing for creditors, perhaps explaining the reticence of creditors to support policy intervention. But there is no reason why lower ex ante lending should be a general result in a richer model than ours. For example, if orderly crisis resolution mean that a crisis country recovers more quickly, investors are likely to be confronted with a greater number of profitable investment opportunities over any given period in time. Creditors are, thus, likely to be unwilling to accept such proposals if the gains are not clearly defined. More generally, this issue raises important questions about measuring global welfare in a regime with policy intervention - one that takes into account both debtor and creditor gains, and weights them accordingly.

It should be stressed that the strength of the case for official sector intervention rests heavily on the extent of the output costs of disorderly liquidations. In the event of the bad state occurring, large-scale termination of short-term debt and litigation to recover contracted debt repayments has to have a significant impact on output. Although the most recent crises have indeed been accompanied by significant declines in output, this is by no means a certainty. The implication is that policy-makers need to establish the likely scale of the costs posed by creditor coordination problems before attempting to intervene. 


\section{Acknowledgments}

We are grateful to Michael Chui, Andrew Haldane, Adrian Penalver, Paul Tucker and the editor, Jonathon Eaton, for helpful comments and encouragement, and to Rosemina Patel for technical support. We thank seminar participants at the International Finance Summer Camp in Santiago, the London School of Economics, the University of Newcastle upon Tyne, the Bank of England, and the Bank of Japan for comments on an earlier version of the paper. The usual caveat applies. The views expressed in this paper are those of the authors and do not necessarily reflect those of the Bank of England.

\section{References}

Allen, F (1983), 'Credit rationing and payments incentives', Review of Economic Studies, Vol 50 (4), pages 639 - 46

Allen, F and Gale, D (1998), 'Optimal financial crises', Journal of Finance, Vol. 53(4), pages 1,254-84.

Bolton, P and Scharfstein, D (1990), 'A theory of predation based on agency problems in financial contracting', American Economic Review, Vol. 80(1), pages 93-106.

Bolton, $P$ and Scharfstein, D (1996), 'Optimal debt structure and the number of creditors', Journal of Political Economy, Vol. 104(1), pages 1-25.

Bolton, $\mathbf{P}$ and Rosenthal, $\mathbf{H}$ (1999), 'Political intervention in debt contracts: moratoria and bailouts', mimeo, Princeton University.

Calomiris, C and Kahn, C (1991), 'The role of demandable debt in structuring optimal banking arrangements', American Economic Review, Vol. 81(3), pages 497-513.

Chang, R and Velasco, A (1998), 'Financial crises in emerging markets - a canonical model', NBER Working Paper, No. 6606.

Chui, M, Gai, P and Haldane, A (2002), 'Sovereign liquidity crises: analytics and implications for public policy', Journal of Banking \&3 Finance, forthcoming.

Clementi, D (2000), 'Crisis prevention and resolution - two aspects of financial stability', Financial Stability Review, Issue 9, pages 154-61.

Diamond, D and Rajan, R (2000), 'Banks, short-term debt and financial crises: theory, policy implications, and applications', NBER Working Paper, No. 7764 . 
Dooley, M (2000), 'Can output losses following international financial crises be avoided?', NBER Working Paper, No. 7531.

Dooley, M and Verma, S (2000), 'Rescue packages and output losses following crises', mimeo, University of California Santa Cruz.

Drage, J and Mann, F (1999), 'Improving the stability of the international financial system', Financial Stability Review, Issue 6, pages 40-77.

Eaton J and Gersovitz, M (1981), 'Debt with potential repudiation - theory and estimation', Review of Economic Studies, Vol. 48, pages 289-309.

Flood, $\mathbf{R}$ and Marion, $\mathbf{N}$ (1998), 'Perspectives on the recent currency crisis literature', IMF Working Paper, No. 98/130.

Grossman, H \& van Huyck, J (1988), 'Sovereign debt as a contingent claims: excusable default, repudiation and reputation', American Economic Review, Vol 78, pages $1088-97$

Institute of International Finance (1996), 'Resolving sovereign financial crises', Washington DC.

IMF (2000), 'International capital markets: developments, prospects, and key policy issues', September, Washington D.C.

King, M (1999), 'Reforming the international financial system - the middle way', Financial Stability Review, Issue 7, pages 203-11.

Kletzer, K (1984), 'Asymmetries of information and LDC borrowing with sovereign risk', Economic Journal, Vol 94, pages 287 - 307

Krugman, P (1979), 'A model of balance of payments crises', Journal of Money, Credit and Banking, Vol. 11, pages 311-25.

Kumar, M, Masson, P and Miller, M (2000), 'Global financial crises: institutions and incentives', IMF Working Paper, No. 00/105.

Miller, M and Zhang, L (2000), 'Sovereign liquidity crisis: the strategic case for payments standstill', Economic Journal, Vol. 110, pages 309-34.

Morris, S and Shin, H S (1998), 'Unique equilibrium in a model of self-fulfilling currency attacks', American Economic Review, Vol. 88(3), pages 587-97.

Morris, S and Shin, H S (2000), 'Rethinking multiple equilibria in macroeconomic modelling', NBER Macroeconomics Annual, MIT Press.

Obstfeld, M (1996), 'Models of currency crisis with self-fulfilling features', $E u$ ropean Economic Review, Vol. 40, pages 1037-47.

Rogoff, K (1999), 'International institutions for reducing global financial instability', Journal of Economic Perspectives, Vol. 13, Fall, pages 21-42.

Scharfstein, D and Stein, J (1990), 'Herd behavior and investment', American Economic Review, Vol. 80(3), pages 465-79. 
Stiglitz, J and A Weiss (1983), 'Incentive effects of terminations: applications to the credit and labour markets', American Economic Review, Vol. 73(5), pages $912-27$.

Summers, L (2000), 'International financial crises: causes, prevention, and cures', American Economic Review, Vol.90(2), pages 1-16. 